mental theorem in the theory of integral equations."

J. L. Coolidge: "The metrical aspect of the line-sphere transformation."

E. J. Miles: "The absolute minimum of a definite integral in a special field."

J. C. Fields: "A method of proving certain theorems relating to rational functions which are adjoint to the fundamental algebraic equation for a given value of the independent variable."

F. F. Decker: "On the order of a restricted system of equations."

Paul Saurel: "On the classification of crystals."

A. B. Coble: "An application of Moore's cross ratio group to the solution of the sextic equation."

A. B. Coble: "The cubic surface and plane sixpoint."

C. L. E. Moore: "Conjugate directions on a hypersurface in $S_{4}$ and some allied curves."

W. H. Bates: "An application of symbolic methods to the treatment of mean curvature in hyperspace."

H. B. Phillips: "The Galois theory of sets of multipartite variables."

J. R. Conner: "Correspondences associated with the rational plane quintic curve."

L. P. Eisenhart: "Conjugate systems and envelopes of spheres."

Joseph Lipke: "Natural families of curves in a general curved space of $n$ dimensions."

O. E. Glenn: "On the discriminants of ternary forms."

Professor Bates's paper will appear in full in the January Transactions. Abstracts of the other papers will be included in the secretary's report in the March number of the Bulletin.

The Chicago Section of the society held its twenty-eighth regular meeting at the University of Chicago, December 28-30. The next meeting of the society will be held at Columbia University on Saturday, February 25.

$$
\begin{aligned}
& \text { F. N. Core, } \\
& \text { Secretary }
\end{aligned}
$$

\section{THE SOUTHERN SOCIETY FOR PHILOSOPHY AND PSYCHOLOGY}

THe sixth annual meeting of the Southern Society for Philosophy and Psychology was held at Chattanooga, Tenn., December 27 and 28, 1910. The meetings were presided over by Professor Edward Franklin Buchner, who delivered the presidential address on the topic: "Learning and Forgetting."
The following papers and reports were read:

Thomas P. Bailey, New York Bureau of $\mathrm{Mu}$ nicipal Research, "Some supposed Racial Tendencies of the American Negro: A Plea for a Psychological Study of the Race Problem."

Jasper C. Barnes, Maryville College, "The Pressure Curve in Voluntary Control."

Knight Dunlap, Johns Hopkins University, "A Study in Rhythm Perception."

David Spence Hill, Peabody College for Teachers, (a) "Some Needs for Child Welfare in the South," (b) "Class and Practise Experiments," (c) "A Comparative Study of Children's Ideals."

A. J. McKelway, secretary, National Child Labor Committee for the Southern States, "Child Labor in its Relation to Education."

R. M. Ogden, University of Tennessee, (a) "The Order of the Days of the Week and the Pythagorean Philosophy," (b) "Knowing and Expressing."

Jno. Pickett Turner, Vanderbilt University, "Locke's Place in the History of Thought."

Tom A. Williams, Washington, D. C., (a) "The Modern Interpretation of Dreams and Visions, Sleeping and Waking," (b) "Intellectual Precocity: The Rôle of the Inclinations and Affectivity: A Comparison of the Principles and Methods employed for educating John Stuart Mill and Boris Sidis's Son."

The officers elected for the year 1911 are:

President-Dr. Shepherd Ivory Franz, Government Hospital for the Insane; Vice-presidentProfessor A. Caswell Ellis, University of Texas.

Secretary-treasurer-Professor R. M. Ogden, University of Tennessee.

Vacancies in the council were filled to constitute that body as follows: for a three-year term, Professors E. F. Buchner, Johns Hopkins University, and W. B. Smith, Tulane University; for a two-year term, Professor Bruce R. Payne, University of Virginia, and President $H$. J. Pearce, Breneau College; for a one-year term, Professors David Spence Hill, Peabody College for Teachers, and W. C. Ruediger, George Washington University.

It was voted to hold the next meeting of the society at Washington, D. C., in affiliation with the American Association for the Advancement of Science, provided the American Psychological and Philosophical Associations meet at the same place and time.

R. M. Oaden, Secretary 